\title{
A final g'day to English general practice
}

\section{BACKGROUND}

I entered general practice in 1988. The 1965 GP charter $^{1}$ influence over the preceding decades convinced me and many of my contemporary graduates from medical school that general practice was 'a worthwhile, effective, and satisfying career with clinical freedom in a personal family doctor service'. ${ }^{2}$ In particular, while preparing for my MRCGP exam in the previous few years I encountered the Leeuwenhorst 1974 definition of general practice ${ }^{3}$ which included the almost poetical phrases: 'The GP is a licensed medical graduate who gives personal, primary, and continuing care to individuals, families and a practice population. It is the synthesis of these functions which is unique', and 'Prolonged contact means that he can use repeated opportunities to gather information at a pace appropriate to each patient, and build up a relationship of trust which he can use professionally'. ${ }^{3}$ This was a truly inspiring job description for me and remains so today (although I suspect the primary gender choice is no longer appropriate).

Competition for general practice partnerships in 1988 was fierce and 30-40 applicants for one post was not uncommon. I felt fortunate to join a similarly enthused GP in Billingham, Cleveland (as it then was) where I worked for a decade.

A mid-life crisis or whatever led me to move to work as a GP in relatively rural Australia in 1999. Certainly the warm climate and outdoor lifestyle were good for my family of five children.

For the last 4 months of last year and first few months of this year I chose to return to the UK NHS taking up a GP maternity locum post in Teesside. I found that general practice in the UK has moved significantly away from the model that attracted me in 1988 and suspect that the changes are more pronounced for me because of my absence for a decade.

\section{OBSERVATIONS}

Meaningful continuity of care of patients by their GP has been compromised in a number of ways.
Patients becoming ill outside fairly standard office hours are no longer assessed by their doctor or his or her partner. Patients in many parts of the country can choose primary care walk-in clinics if this is geographically or otherwise more convenient for them than their registered practice. Within their own practice, patients may see different practitioners (and sometimes nurses rather than doctors) for different chronic diseases (for example, asthma, diabetes, and ischaemic heart disease), or indeed different practitioners for episodes of the same acute or chronic illness (because this is the easiest way to provide the flexibility of practice appointment provision in response to the consumerist diktat of government for patients to be seen quickly after their request for an appointment). Extra appointment capacity within practices (but not usually with the patient's 'usual doctor') has been recruited to make sure that Quality and Outcomes Framework (QOF) targets are met. Some fairly basic services previously provided by GPs have essentially been hijacked by other providers (antenatal obstetric care by community midwives or hospital clinics and drug abuse by specialist primary care services, for example).

Also gone are the cosy personal and red tape-free lines of communication between GPs and other primary care professionals and secondary care practitioners (wither the Leeuwenhorst 'He will practise in cooperation with other colleagues, medical and non medical'). ${ }^{3}$

I left a practice in 1999 where the district nurse, community midwife, and health visitor all worked from the practice premises and served the same (practice) population. Formal meetings occurred regularly but even more important were the informal meetings at morning tea breaks or even in the car park. Mutual concerns about patients were exchanged face to face and respectful and trusting professional relationships were developed. We understood each others roles and primary concern for patients through this process. Requests to see patients and, in particular, to make timeconsuming home visits were respected and not questioned.

In contrast, the current GP referral path for district nursing care for patients is through an administrative hierarchy (and other services work similarly). Tasks are then allocated to one of a team of district nurses in the area with no close attachment to particular practices. Communication in both directions are usually via telephone messages through the practice reception staff. There is no easy way of knowing which district nurse will be attending a specific patient and because of the number of different nurses covering the practice population it does not seem possible to develop a meaningful relationship with any. Requests tend to be responded to or not by reference to fulfilling specific criteria rather than a concern to act as a team to look after the patient.

Similarly, in referral to secondary care, the personal aspects of communication between GP and specialist have been removed. In 1999 I would know the clinical expertise and bedside manner of most of the specialists at the district general hospital to whom I referred most of my patients. I could match patients to the appropriate specialist accordingly and be confident of the care they would receive. The specialists in turn came to be aware of my strengths and weaknesses. They would understand when my referrals required a simple defined service from them or when I was needing a genuine second opinion and help with a worrying but poorly defined problem. They would respond accordingly. This type of relationship was developed from longterm working relationships. It arose from a continuing personal dialogue of referral letters and replies, direct telephone discussion about the need for referral or general clinical advice and not infrequent face-to-face contact made at regular postgraduate meetings at the local hospital.

The current referral system in Teesside 
is a triumph for faceless consumerism and production line ethics. The Teesside flavour of Choose and Book dictates that the GP decides which specialty, or indeed sometimes very narrow sub-specialty, the patient should seek services from but then the patient decides on accessibility convenience criteria which hospital to attend. It is not possible to specify the name of the responsible specialist. Sometimes the choice of sub-specialty will be questioned (which is not surprising as primary care presentations do not always fit neatly into secondary care specialty categorisations) by intermediaries in the referral process. Usually this results in simply bouncing the referral back to the GP rather than attempting to help in re-directing it. Invariably referral replies are impersonal and fail to make any connection with the particular referring GP. Indeed it often appears to me that the referral letters have not even been read. Frequently, referrals for clinical problems emerge from the system with performance of a negative diagnostic procedure noted but no solution to the presenting problem or advice on any further management.

The variety of provider institutions (NHS and private hospitals and consulting and diagnostic facilities, GPs with special interests and so on) for me creates confusion rather than free market optimism. It was much clearer with the old district general hospital one-stop shop. It was transparent in this case which services were available and which were underfunded or unavailable. For my patients, I felt there were also advantages for one location to provide and coordinate most of their secondary NHS care.

I also have concerns for the wellbeing of current medical graduates choosing general practice.

Chronic disease management is a huge component of contemporary primary care. Understanding how our high quality evidence-based chronic disease guidelines can be applied to individual patients is an experientially gained clinical skill founded on face-to-face contact with patients rather than a dry intellectual exercise. It has always been hard to involve trainees and new GPs meaningfully in this (with the tendency for patients with chronic diseases to be cared for by established GPs) but it is even harder now for a basic understanding of routine care to occur when much of the care for the more common chronic diseases is performed by dedicated practice nurses. Without practical expertise I find it hard to understand how future GPs will be able to claim a central role in chronic disease management in primary care. And without that, what is left of the GP role?

It is disappointing too that many currently well-paid GP principals chose to maintain their income and wealth at the expense of doctors emerging from GP training. Retiring partnership principals are most commonly replaced with longterm assistantships or even nurse practitioners. Small practices are increasingly being sold to multi-practice corporate organisations in preference to handing on to doctors entering general practice. These organisations are primarily driven by profit and particularly keen to explore cheaper ways of delivering primary 'care' that do not involve old style general practice models and do not provide for independent selfdetermination for their employed doctors. There would seem to be an increasing divide between the established GP principal 'haves' and the new entry 'havenots' and there is no longer any sense of collegiate welcome of newcomers to general practice as equals. I cannot see such a situation engaging the aspirations of new medical graduates for much longer.

\section{G'DAY}

One of my reasons for returning to the UK from Australia was to spend some time with my fading parents. It seems to me that the general practice referred to by those inspirational Leeuwenhorst statements is withering away too (particularly the ones referring to continuing care and the chances, even through relatively trivial clinical interactions, to develop over time the trusting relationship of importance when the serious problems arise). The demise has been brought about by government intent (for whatever reason independent professionals with strong power bases seem to be perceived as a threat and something to control even if the services they provide are of a high quality and are cost-efficient), complicity of doctors themselves (allowing the government to 'divide and conquer' and putting personal gain ahead of care and protection of a valued professional way of life), and political apathy of our patients (the majority of whom are relatively well and not requiring on a daily basis the personal and continuing care of the more vulnerable among the population).

The evolution of primary care in the UK has left me with little doubt now that most of the everyday processes of primary care can be conducted successfully and more cost-effectively, through protocol-driven screening and identified chronic disease care by health professionals who do not need the expensive broad base of medical training and status-derived salaries enjoyed by today's GPs. I do not begrudge the opportunities, laudably encouraged in the UK, for nurses and other health professionals to expand into this work in primary care (and in other parts of the health system) - I have worked with many highly skilled and motivated colleagues from these professions in my 20 years as a GP and rejoice in the formal recognition of their worth and potential. It may also be possible (but yet to be proven), that the relatively small number of more complex multi-disease and multidimensional combinations of physical, psychological, and social problems in patients presenting to primary care can be assessed and managed by further such evolutions of nurse practitioners (but without the benefit of the trust-derived relationship built up over years of less critical clinical interactions in the traditional GP model).

With the changes I have mentioned 
already in place and the pace of further change currently occurring it is hard to turn the clock back, nor indeed might it be appropriate on health, economic, or current political grounds to even try.

So it seems to me that English general practice had a good and worthwhile life which is now ending.

At the end of my time in the UK both my parents died. They too had good, long, and worthwhile lives but the quality of life in their last few months was not good. Such rationalisations do not seem to make the loss any easier to bear though.

My father died 8 days after my mother - I had not come to terms with the loss of one parent before I had lost another. For now, I have returned to a style of general practice in rural Australia that, by chance, remains closer to the ideals that inspired me during my UK training in the 1980s. But where English general practice goes, Australian practice tends to follow (like my parents' intertwined destinies) and I do not think it will be long before I have more mourning to do.

\section{Adrian Elliot-Smith}

\section{REFERENCES}

1. British Medical Association. Charter for the family doctor service. London: BMA, 1965.

2. Rivett G. From cradle to grave: fifty years of the NHS London: King's Fund, 1998.

3. The work of the general practitioner. A working party of the second European conference on the teaching of general practice. J R Coll Gen Pract 1977 February; 27(175): 117.

DOI: 10.3399/bjgp09X453918

\section{COMMENTARY}

'Don't worry about the world coming to an end today. It's already tomorrow in Australia'. Charles M. Schulz US cartoonist (1922-2000).

'A final g'day to general practice' is a poignant and thought-provoking commentary on modern general practice. ${ }^{1}$

As a young GP myself, I see disillusionment among my peers. The emerging two-tier system and a sense of 'tick-box medicine' create dissatisfaction among new and old doctors alike. It is little wonder that many young doctors are following the author's lead and emigrating to $\mathrm{Oz}$.

Interesting too are the comments on communication with our hospital colleagues. Last week I met a paediatric oncologist who reminisced mournfully about GPs phoning for 'a bit of advice' and expressed a real enthusiasm for more human contact. Choose and Book has yet to reach Scotland but clearly it may widen the communication gap further.

Despite this, general practice remains, I think, a highly rewarding job with much hope and promise for the future. The RCGP publication The Future Direction of General Practice states that 'The generalist who can provide holistic and patient-centred care is needed now more than ever'. ${ }^{2}$

Perhaps then it is not time to mourn for the loss of general practice but rather to fight to keep it alive. With the words of Thomas Jefferson, 'A little rebellion now and then ... is a medicine necessary for the sound health of government'.

\section{Faye McCleery}

GP Retainer, Wishaw Health Centre.

\section{REFERENCES}

1. Elliot-Smith A. A final g'day to English general practice. Br J Gen Pract 2009; 59: 618-620.

2. Royal College of General Practice. The Future Direction of General Practice. A roadmap. http://www.rcgp.org.uk/PDF/Roadmap_embargoed\%2011am\%2013\%20Sept.pdf (accessed 9 Jul 2009).

DOI: 10.3399/bjgp09X453927

\section{Book review}

\author{
JOSEPH'S BOX \\ SUHAYL SAADI \\ Two Ravens Press, Scotland, 2009 \\ pp670, £13.99, ISBN: 9781906120443
}

This is a big book, in every way: it is excessive, extravagant, exuberant, exhilarating, erotic, esoteric, entertaining, entrancing and eccentric; and like the boxes that give it a structure, of sorts, it contains layer upon layer of allusions and connections. The narrative sweeps across continents, and the cultural references include everything from hip hop to classical verse forms of the Moghul emperors. The psychological landscape ranges from the hard realities of what we are used to calling, rather primly, 'the doctor-patient relationship' (transgressed in the most shocking way) to hallucinatory meanderings along the wilder shores of the subconscious.

Zuleikha Chasm Framareza MacBeth (Zulie for short) is a middle-aged GP grieving the loss of her Afghani mother and, some years earlier, of her only son Dhaoud. On an evening of despair she wanders along the banks of the Clyde and finds, bobbing in the current, a strange box. With the help of another recently bereft wanderer, Alex Wolfe, she retrieves the box, and they take it back to her flat. There they begin the adventure of unravelling the spells that lock each of the seven nested boxes, deciphered through Alex's magical mutating lute and his computational skills.

Other significant characters include Archie McPherson, once an aircraft engineer, now a patient of Zulie's, dying of mesothelioma yet imbued with a power over his doctor that she can neither explain nor resist; Laila Asunsi, 'ageing hippy' extraordinaire who lives in an old house near a Lincolnshire aerodrome where Archie once worked, danced, and made love; Peppe Ayala, Sicilian cousin of Laila and an archaeological historian; Petrus Dihdo Labolka, a juggler and impresario of RussoPunjabi parentage, ex-lover of Laila living in Lahore; and young Zulfikar Ali Lobsang, a Baltistani guide who takes Zulie and Alex on their final enlightening journey to the high mountains of Ladakh, where their weird 